\title{
A SIMPLE MODEL USED IN SOFTWARE QUALITY EVALUATION FOR THE ECONOMIC APPLICATIONS
}

\author{
Anamaria Şiclovan ${ }^{1}$ \\ Al. I. Cuza University of Iaşi \\ agapin_ana @yahoo.com
}

\begin{abstract}
It was noted that, over the time, in the field of economic informatics and economy, most people have become dependent on software applications. Do economic applications reach a high threshold of quality such as to satisfy the customers who are dependent on them? This study proposes to present a model that analyzes the quality of economic applications. By applying this model, we could tell if an economic application which is submitted to the analysis reach a certain quality threshold or not. Thus, by analyzing the factors and sub-factors that characterize any economic application, we can analyze the software quality.
\end{abstract}

\section{Keywords}

model; software quality; evaluation of software quality; quality factors

\section{JEL Classification}

C02; D20; D11

\section{Introduction}

Quality culture is an important component in the society we live, which justifies the choice of this subject in the presence of research topics. Quality management is an integral part of the management science. Therefore, the quality is a vital part when dealing with products and services.

Quality tends to be one of the key points of the economic success in our world. The concept of quality in the economy is based on the theory of meaning developed by Joachim Von Uexküll (Ioniţă, 2002). According to this theory, the image of a product is represented by its features. The feature is a quality product which distinguishes it from others and derives from its value in use, so from the product's property to meet a social need. Total Quality Management (Total Quality Management - TQM) is an integrated effort at the organization level meant to improve the quality at each level of it. The historical development of total quality management comprises four stages: quality inspection, quality control, quality assurance and, finally the TQM process itself, Quality is obvious in human actions.

According to Christian Potié (2001), total quality management includes "all the priorities and characteristics of an organization that gives the aptitudes to meet internal and external quality requirements, searching for all the competitive advantages." Total Quality Management is viewed through an additional competitive advantage for the company and not only, through searching the customer's satisfaction. And this is particularly more appropriate as almost all the companies practice or claim to practice total quality management. Thus, the customer's satisfaction is not a discriminating factor if it provides a competitive advantage. Ensuring the product quality is achieved gradually, as it progresses in the process of obtaining it. The quality of a system is created starting with the creation period of the

\footnotetext{
${ }^{1}$ Phd at Al. I. Cuza University of Iaşi
} 
product and is manifested, is highlighted when in use. In software engineering there is a dependency between the quality of the software development process, between the quality project and product.

In the current competitive context of the new technologies (the calm technologies), the performance of an organization requires the development of the applications to take place at a quality level that can ensure the quality of their operation, both in terms of enterprise management and through the technologic process of their development. Ensuring the quality in an economic application involves accession to a large amount of current information regarding the quality and to a complex process of analysis and synthesis.

The ability of the organization to choose an economic quality application is an important step in the development and the proper functioning of this structure, because the quality refers to the level at which the application manages to cover the maximum number of requirements. In the early development of an economic application, the customer's requirements, of the recipient are on the first place and, of course, at the end of it. Between these two moments the application development takes place.

With the development of information technology, the concept of quality, quality analysis and quality improvement has become a strong area to be analyzed. Thus, in the field of quality of the economic applications there have been quality assessment models for the informatics applications, marketing ones, and communication ones (Bezes, 2009). For the determination and interpretation of the software quality it was necessary the software quality evaluation analysis. The software quality assessment process means to identify the quality objectives, the product component selection, choosing appropriate techniques and instruments, measurements and reporting.

Nowadays, the software applications prevail in all the fields: business, education and, especially in the informational one. Targeted to support changes so as to keep up with the quality issues, the economic applications are on the first place. Thus, while respecting the factors conducive to meeting the needs of the customers, there is a successful e-commerce. Many organizations are forced to abandon traditional applications in favor of modern applications, to adopt the current economic applications that meet the quality standards and that are subject to development and competitiveness (Liu et al, 2007).

\section{Literature review}

We can confirm a software as being of quality if a user's desired features are incorporated into the software so that performance of the software is improved. Regarding the above analysis, we can say that a soft reaches quality if all its components such as: programs (codes), procedures, data and documentation meet the quality criteria.

The effort made to analyze the quality of a software application dates from 1970. McCall, Richards and Walters (1977) were among the first researchers who analyzed the concept of quality for the software applications and had given quality factors to software systems. The quality factors for a software application indicates the behavior characteristics of this application.

According to the IEEE standard (1991), the software quality is regarded as (Galin, 2004):

- The degree to which a system, component or process meets the specified requirements;

- The degree to which a system, component or process meets the customer's or the user's needs and expectations. 
These two alternatives of defining the software offered by the IEEE package standards, represents the starting point for researchers such as Crosby in 1979 and Juran in 1988. In order to understand the process of software quality assurance, we had to accept and understand what the quality of a software application is. The quality assurance of the final product is achieved gradually, while it advances in the process of obtaining. The quality of a software application is being formed from the product's development process and it is emphasized in the process of use thereof.

Firstly, the overall theme of the quality treatment issues positively influences the understanding of these issues by consumers, web designers and evaluators of the application systems. Moreover, the attention focused on the consumer who wishes to receive quality influences the quality issues. We will schematically present, in the following figure, the importance of the quality assessment, since the quality

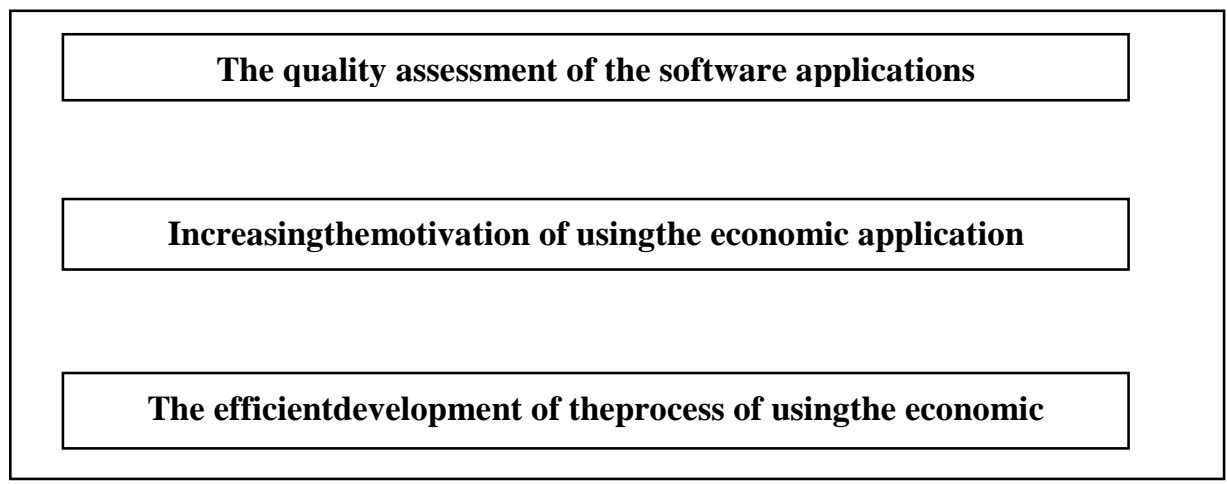

Figure1 The economic benefits of the quality assessment applications and their relationship

We can mention that a good use of the application, a deep understanding of all that is the developed functions of this application, represents the increase of dependency of the application use and, therefore, the qualitative assessment of that application.

Next, we will present some results on a timeline in the field, to motivate the proposed model that we consider suggestive in this research:

- Aladwani\&Palva (2002) developed a tool that captures the key features of a quality web site from a user's perspective;

- Olsina (2002) evaluates the quality of websites by applying the WebQEM method.

- Chen, Tang \& Cheng (2005) developed a quantitative evaluation index system of quality for the B2C sites, index which does not focus on the income's site, but on the quality synthetic evaluation. It is hoped that this index improve the quality and help the managers to take good decisions in the operation site.

- Parasuraman\&Zeithaml (2005) developed a model that consists in synchronizing the other two models: ES-Qual and E-RECs-Qual.

- Djajadikerta\&Trireksani (2006) developed an instrument by assigning responses to 23 items. The 23 items can be used as a basis for designing and developing a more efficient site for a university.

- Alhelalat et al. (2008) showed the interdependence of the main conceptual components specific to the accomodation site. The following factors are analyzed: the quality of information, the quality of services. 
- Khawaja \& Bokhari (2010) test and classify the factors contributing to adding quality to the website of the university and measures the development degree of satisfaction. The purpose of this research is to explore which factors determine the quality of the University's website. The purpose of this study continued with the application of the SERVQUAL instrument leading to measure the quality of university websites.

- Karim (2011) developed its own model. This model was implemented to test the factors that disrupt the user's satisfaction. The research combines three different methods: the exploitation which selects from the group of factors only those factors that influence the consumer's satisfaction, the second method was the descriptive one which shows the profile sample and the third one, in which has been analyzed the relationship between dependent and independent variables.

- Elangovan (2013) - the methodology is based on WebQual-4 tool developed for the purpose of the article, for the software quality evaluation.

This presentation of models and tools presented in the field explains our tendency to propose a new model of software quality approach. As we can observe from the centralization of results in the literature, the development trend of a new instrument to measure the quality attributes had the highest degree. The researchers' idea was that, through their own vision and using a new instrument, they will be able to find the perfect method of measurement.

\section{Proposing a simple model to assess software application}

The model that we propose will be called an INT-Application EC. This model is especially designed to perform an analysis of the influence degree brought by the quality factors when interacting with the economic application used. For this, two important indicators of interaction were proposed, namely:

I1. Does interaction helps to input / output data?

I2. Does interaction helps orient the application?

In the second stage, the quality factors were grouped, taking as reference their presentation as in Olsina's model. The factors were grouped into four categories that contain specific sub-factors.

Table 1. The factors analyzed in interaction

\begin{tabular}{|l|l|l|l|}
\hline Factor & Subfactor & Value for I1 & Value for I2 \\
\hline \multirow{5}{*}{ Usability } & Global understanding & 1 & \\
\cline { 2 - 4 } & Feedback characteristics & 1 & \\
\cline { 2 - 4 } & $\begin{array}{l}\text { Interface and aesthetic } \\
\text { characteristics }\end{array}$ & & 2 \\
\cline { 2 - 4 } & Different characteristics & 1 & 2 \\
\hline Functionality & Search and retrieval problems & & 2 \\
\cline { 2 - 4 } & Navigation problems and specific & 1 & 2 \\
\cline { 2 - 4 } & $\begin{array}{l}\text { Functionality } \\
\text { content }\end{array}$ & & 2 \\
\hline Confidence & Lack of deficiencies & & 2 \\
\hline Efficiency & Performance & & 2 \\
\cline { 2 - 4 } & Accessibility & & 2 \\
\hline
\end{tabular}


In preparing the model we applied the Pareto principle which led to the following applicable index:

$$
f\left(F_{1}, F_{2}, F_{2}, F_{4}\right)=20 \% \bar{f}+80 \% \bar{F}
$$

The questions related to subfactors are grouped by categories to which they are addressed. In the next section, we will present the questions that help us to ensure the verification of the degree to which the quality factors influence the interaction.

Questionnaire on quality issues for the economic application:

\section{Usability}

Global understanding

-Does the economic application have a global organization system?

-Does the economic application have a quality labelling system?

-Does the economic application have an oriented audience guide?

-Does the economic application have a map of images?

Characteristics of feedback:

-Does the economic application have features of Help?

-Does the economic application contain folder sharing?

-Does the economic application have a feedback-based links?

-Does the economic application have any form-based feedback?

Interface and aesthetic characteristics

-Does the economic application have cohesion by grouping the main control objects?

-Does the economic application have a performant presentation and stability of the main controls?

-Does the economic application have issues of style?

Miscellaneous features:

-Does the economic application have support for foreign languages?

-Does the economic application hold an indicator for the last amendment on the site?

-Does the economic application hold an indicator screen resolution?

\section{Functionality}

Search and retrieval problems:

-Does the economic application present mechanisms search?

-Does the economic application have the ability to take the mechanisms for search and retrieval problems?

Problems of navigation:

-Does the economic application present navigability?

-Are there any control objects found in the navigation?

-Does prediction appear in navigation?

-Are there the search mechanisms present?

\section{Reliability}

Lack of deficiencies:

-Are there in the economic application any incorrect links?

-Are there in the economic application any mistakes in spelling?

-Does the economic application present errors or diverse disadvantages? 


\section{Efficiency}

Performance

-Does the economic application have static pages?

Accessibility

-Are the information in the economic application available?

-Are the windows of the application available?

\section{Conclusion}

This theoretical model will be applied in the future research on the UMS software, software used by 25 universities in the country and abroad. This model through its own application determines the management support of the organization because it leads to a strict quality evaluation of the UMS application.

With this model we can assess the degree to which the quality factors influence through interaction the use of this software. The interaction with an educational software is particularly effective as the quality factors are better implemented in that application. The quality evaluation for this economic application-UMS is a landmark for all the universities which use this portal.

\section{References}

Aladwani, A.M., \&Palvia, P.C. (2002). Developing and validating an instrument for measuring user-perceived web quality. Information \& Management, 39, 467476.

Alhelalat, J., Ineson, E.M., Jung, T., \& Evans, K. (2008). The Evaluation of Hotel Websites' Quality, Usability and Benefits: Developing a Testing Model. Proceedings of Euro-CHRIE Conference. Dubai, UAE, October.

Bezes, C. (2009). E-commerce website evaluation: a critical review.

Chen, M., Tang, B., \& Cheng, S. (2005). An Index System for Quality Synthesis Evaluation of BtoC Business Website. Proceeding ICEC '05 Proceedings of the 7th international conference on Electronic commerce. 75-77.

Djajadikerta, H., \& Trireksani, T. (2006). Measuring University Web Site Quality: A Development of a User-Perceived Instrument and its Initial Implementation to Web sites of Accounting Departments in New Zealand's Universities.

Elangovan, N. (2013). Evaluating Perceived Quality of B-School Websites. IOSR Journal of Business and Management (IOSR-JBM). 12 (1), 92-102.

Galin, D, Software Quality Assurance. From theory to implementation. Pearson Education, England, 2004, p 24.

Karim, A., J. (2011). Evaluating the influence of reability, usability, usefulness and websites design on the satisfaction of online consumers. Research Journal of Economics, Business and ICT, 2, 28-32.

Khawaja, M., K., F., \& Bokhari, R., H. (2010). Exploring the factors associated with quality of websites. Global Journal of Computer Science and Technology, 10(14), 37-45.

Liu, Y., Kwon, Y., \& Kang, B. (2007). A Fuzzy AHP approach to evaluating ecommerce websites. Proceedings of the 5th ACISInternational Conference on Software Engineering Research,Management \& Applications (SERA2007) (pp. 114 - 124). CA, USA: IEEE Computer Society, 20 - 22 August 2007, Busan, South Korea, Los Alamitos. 
McCall, J. A, Richards, P. K., Walters, G. F., Factors in Software Quality, Technical Report RADC-TR-77-369. U.S. Department of Commerce, Washington, DC, 1977

Olsina, L., \& Rossi, G. (2002). Measuring Web Applications Quality of WebQEM. Journal IEEE MultiMedia, 9(4), 20-29.

Parasuraman, A., Zeithaml, V. (2005). E-S-QUAL A Multiple-Item Scale for Assessing Electronic Service Quality. Journal of Service Research, 7(10),1-21 